\title{
Malmquist Productivity Index with Grey Data
}

\author{
Kenan Oguzhan Oruc ${ }^{1}$ \\ 1 Faculty of Economics and Administrative Sciences, Department of Econometrics, Süleyman Demirel \\ University, Turkey \\ Correspondence: Kenan Oguzhan Oruc, Faculty of Economics and Administrative Sciences, Department of \\ Econometrics, Süleyman Demirel University, Turkey. E-mail: kenanoruc@sdu.edu.tr
}

Received: July 16, $2015 \quad$ Accepted: August 17, $2015 \quad$ Online Published: September 18, 2015

doi:10.5539/ijbm.v10n10p186 URL: http://dx.doi.org/10.5539/ijbm.v10n10p186

\begin{abstract}
Malmquist Productivity Index (MPI) is widely used method to measure the productivity changes of Decision Making Units (DMUs) between two time periods. Although the conventional MPI requires accurate data, in many real life conditions the input and output data of DMUs usually involve uncertainty and only lower and upper bounds of data could be obtained. Grey (number) theory is one of the theories which are used for describing uncertainty. A grey number, with both a lower and upper bounds, is called an interval grey number. The purpose of this paper is to measure the productivity changes under uncertainty conditions based on the interval grey number theory. In the paper, new grey MPI models are proposed to measure productivity changes of DMUs which have interval data. A numerical example is provided to illustrate the application of the proposed models. Results of the numerical example show us that the proposed models are easy to handle and applicable for real life problems.
\end{abstract}

Keywords: distance functions, grey number, Malmquist productivity index, whitenization

\section{Introduction}

Data Envelopment Analysis (DEA) is a nonparametric method to measure the relative efficiencies of enterprises (Decision Making Units-DMUs) which use multiple inputs in order to produce multiple outputs. In the efficiency measurement of DEA, different production functions are defined for each DMU and DMUs that are producing maximum output(s) by using minimum input(s) constitute the efficiency frontier by enveloping all possible producible input-output combinations. Efficiency values of DMUs are measured according to the distance to efficiency frontier. DEA can be used to calculate the relative efficiency measurement at a specific time period.

Fare et al. $(1992,1994)$ developed DEA based MPI which measures the productivity change of DMUs over time. The Malmquist Index was first suggested by Malmquist (1953) as a quantity index to be used in the analysis of consumption of inputs. Fare et al. (1992) combined ideas on the measurement of efficiency from Farrell (1957) and the measurement of productivity from Caves et al. (1982) to construct a MPI directly from input and output data using DEA (Chen \& Ali, 2004).

Although conventional MPI requires all inputs and outputs of exact values of DMUs, in reality the data of DMUs often include ranges (interval data) and implies uncertainty. Grey system theory which is developed by Deng (1982) is a mathematical method to solve problems containing interval data which are named as grey numbers. Although there are studies in the literature of the measurement of MPI with interval data by using fuzzy set theory, a study using grey system theory/numbers has not been reached.

The aim of this paper is to propose grey MPI models for DMUs with interval grey data. In the paper, interval grey input and output data are whitenized by using equal weight whitenization and equal weight mean whitenization functions.

The rest of the paper is presented as follows: The literature is reviewed in section 2. MPI method and distance function formulations are described briefly in section 3. Section 4 overviews grey system theory as well as some fundamental definitions and functions on grey numbers. New grey MPI approaches are introduced in section 5 . In section 6, a numerical example is provided to illustrate proposed models. Finally, conclusions are drawn in the last section. 


\section{Literature Review}

Under uncertainty conditions, measurement of MPI has not been studied extensively in the literature and in all the studies conducted; fuzzy set theory is applied to describe uncertainty. From the optimistic and pessimistic viewpoint, Jahanshahloo et al. (2006) measured upper and lower bounds of MPIs by using $\alpha$-level based approach. To apply the model, the number of distance function model must be as follows: number of DMUs*8 for each $\alpha$-level. In this respect, the application of the model takes a long time. Jahanshahloo et al. (2007) proposed a model in which fuzzy data is transformed to crisp data by using linear ranking function. Lotfi et al. (2009) developed the distance function model by using ranking of L-R fuzzy data based on the comparison of $\alpha$-level. In order to apply the model, for each $\alpha$-level, the number of distance function model must be set up as follows: number of DMUs*4. Emrouznejada et al. (2011) developed a model that not only for measuring MPI, but also measuring the change in the level of profit. In this study, the price data of input and output that is fuzzy is applied. The model provides the maximum value of distance functions for any $\alpha$-level. Hatami-Marbini, Tavana \& Emrouznejad (2012); developed a model that distance functions are established as primal DEA models In this proposed model, the numbers 0 and 1 are taken as fuzzy. In the establishment of the model $\alpha$-level and variable transformation are used. Payan and Sharifi (2013) used the credibility theory as a basis in their studies. In the study, the objective function and fuzzy constraints are defined as a fuzzy case. The fuzzy DEA models are first defuzzied by applying the credibility theory. The obtained results are used for calculating MPI on fuzzy data.

\section{Malmquist Productivity Index}

MPI, which is defined in terms of distance functions, measures the productivity change of a DMU between two time periods. The distance function can be presented as an input distance function or an output distance function. If $x^{t}$ denotes an input vector and $y^{t}$ an output vector at period $t$, then the production technology is the set $S^{t}$. Input distance function at period $t$ is defined as (Fare et al., 1992)

$$
D_{i}^{t}\left(y^{t}, x^{t}\right)=\sup \left\{\lambda:\left(\frac{x^{t}}{\lambda}, y^{t}\right) \epsilon S^{t}\right\}=\left[\inf \left\{\lambda:\left(\lambda x^{t}, y^{t}\right) \epsilon S^{t}\right\}\right]^{-1}
$$

while the output distance function is expressed as follows (Fare et al., 1994)

$$
D_{o}^{t}\left(x^{t}, y^{t}\right)=\inf \left\{\theta:\left(x^{t}, \frac{y^{t}}{\theta}\right) \in S^{t}\right\}=\left[\sup \left\{\theta:\left(x^{t}, \theta y^{t}\right) \in S^{t}\right\}\right]^{-1} .
$$

There is a relation $\left[D_{i}^{t}\left(y^{t}, x^{t}\right)\right]^{-1}=D_{0}^{t}\left(x^{t}, y^{t}\right)$ between input and output distance functions. Input distance function measures the largest possible contraction of $\mathrm{x}^{\mathrm{t}}$, while output distance function measures the reciprocal of the maximum proportional expansion of the output vector $\mathrm{y}^{\mathrm{t}}$.

As in the distance functions, MPI can be calculated input or output based as well. Output based MPI between periods $t$ and $t+1$ can be evaluated with the following equation (Fare et al., 1994):

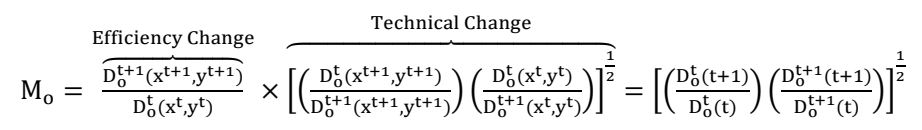

MPI bases the reason of productivity changes on the efficiency change and technical change. Efficiency change measures relative technical efficiency at periods $t$ and $t+1$, that is, whether production is getting closer or farther from the efficiency frontier. Technical change is the geometric mean of two productivity indexes and measures the shift in the efficiency frontier between periods $t$ and $t+1$. After calculations $M_{o}$ can take three different values. $M_{0}>1$ denotes productivity growth, while $M_{0}<1$ indicates productivity decline, and $M_{0}=1$ means no change in productivity from period $t$ to $t+1$ (Fare et al., 1994).

Distance function calculation requires two single periods $\left[D_{0}^{t}(t)\right.$ and $\left.D_{o}^{t+1}(t+1)\right]$ and two mixed periods $\left[D_{o}^{t}(t+1)\right.$ and $\left.D_{o}^{t+1}(t)\right]$ measures (Chen \& Ali, 2004). A set of $n$ DMUs consume a set of $m$ inputs $\left(\mathrm{x}_{\mathrm{ij}}\right)$ to produce a set of $s$ outputs $\left(\mathrm{y}_{\mathrm{rj}}\right)$ at periods $\mathrm{t}$ and $\mathrm{t}+1$. Distance functions for $\mathrm{k}^{\text {th }} \mathrm{DMU}$ can be denoted as below: 


$$
D_{o}^{t}(t)=\max \sum_{r=1}^{s} u_{r} y_{r k}^{t}
$$

s.t.

$\sum_{\mathrm{r}=1}^{\mathrm{s}} \mathrm{u}_{\mathrm{r}} \mathrm{y}_{\mathrm{rj}}^{\mathrm{t}}-\sum_{\mathrm{i}=1}^{\mathrm{m}} \mathrm{v}_{\mathrm{i}} \mathrm{x}_{\mathrm{ij}}^{\mathrm{t}} \leq 0$

$\mathrm{j}=1, \ldots \mathrm{n}$

$\sum_{i=1}^{m} v_{i} x_{i k}^{t}=1$

$\mathrm{v}_{\mathrm{i}}, \mathrm{u}_{\mathrm{r}} \geq 0$

$\forall \mathrm{i}, \mathrm{r}$

$D_{o}^{t+1}(t)=\max \sum_{r=1}^{s} u_{r} y_{r k}^{t}$

s.t.

$\sum_{\mathrm{r}=1}^{\mathrm{s}} \mathrm{u}_{\mathrm{r}} \mathrm{y}_{\mathrm{rj}}^{\mathrm{t}+1}-\sum_{\mathrm{i}=1}^{\mathrm{m}} \mathrm{v}_{\mathrm{i}} \mathrm{x}_{\mathrm{ij}}^{\mathrm{t}+1} \leq 0$

$\mathrm{j}=1, \ldots \mathrm{n}$

$\sum_{i=1}^{m} v_{i} x_{i k}^{t}=1$

$\mathrm{v}_{\mathrm{i}}, \mathrm{u}_{\mathrm{r}} \geq 0$

$\forall \mathrm{i}, \mathrm{r}$ \begin{tabular}{|ll}
$D_{0}^{t+1}(t+1)=\max \sum_{r=1}^{s} u_{r} y_{r k}^{t+1}$ & \\
s.t. & \\
$\sum_{r=1}^{s} u_{r} y_{r j}^{t+1}-\sum_{i=1}^{m} v_{i} x_{i j}^{t+1} \leq 0$ & $j=1, \ldots n$ \\
$\sum_{i=1}^{m} v_{i} x_{i k}^{t+1}=1$ & \\
$v_{i}, u_{r} \geq 0$ & $\forall i, r$
\end{tabular}

$$
\begin{array}{ll}
D_{o}^{t}(t+1)=\max \sum_{r=1}^{s} u_{r} y_{r k}^{t+1} & \\
\text { s.t. } & \\
\sum_{r=1}^{s} u_{r} y_{r j}^{t}-\sum_{i=1}^{m} v_{i} x_{i j}^{t} \leq 0 & \\
\sum_{i=1}^{m} v_{i} x_{i k}^{t+1}=1 & \\
v_{i}, u_{r} \geq 0 & \forall i, r
\end{array}
$$

$D_{o}^{t}(t)$ measures distance of $\left(x_{k}^{t}, y_{k}^{t}\right)$ to the efficiency frontier at period t. Similarly, the other single period $D_{0}^{t+1}(t+1)$ measures distance of $\left(x_{k}^{t+1}, y_{k}^{t+1}\right)$ to the frontier at period $t+1$. Mixed periods; $D_{0}^{t}(t+1)$ measures distance of $\left(x_{k}^{t+1}, y_{k}^{t+1}\right)$ to the frontier at period $t$, while $D_{o}^{t+1}(t)$ measures distance of $\left(x_{k}^{t}, y_{k}^{t}\right)$ to the frontier at period $\mathrm{t}+1$.

\section{Grey System Theory and Grey Numbers}

Deng (1982) introduced the grey system theory as a tool for studying system uncertainty (Hajiagha, Zavadskas, \& Hashemi, 2013). This theory is a decision making method for studying uncertain problem with less data and poor information. The theory studies on the small sample, poor information systems with partial information known, partial information unknown. It describes correctly and monitors effectively system's operation and evolution, through extracting valuable information from known information (Liu \& Forrest, 2007). In grey system theory, completely known information is named as white systems, systems with completely unknown information as black systems, and systems with partially known and partially unknown information as grey systems, respectively (Liu \& Lin, 2006).

Grey number, which is used to describe uncertain or partially known information, is the basic element of grey systems theory. A grey number is such a number whose exact value is unknown but a range within that the value lies is known. In applications, a grey number in general is an interval or a general set of numbers (Liu \& Lin, 2006).

Definition 1: A grey number with both a lower limit $\underline{\mathrm{x}}$ and an upper limit $\overline{\mathrm{x}}$ is called an interval grey number, denoted as $\otimes_{\mathrm{x}} \in[\underline{\mathrm{x}}, \overline{\mathrm{x}}]$.

Definition 2: When $\otimes_{\mathrm{x}} \in[-\infty, \infty]$ or $\otimes_{\mathrm{x}} \in\left[\otimes_{1}, \bigotimes_{2}\right]$, that is, when $\bigotimes_{\mathrm{x}}$ has neither an upper limit nor lower limit, or the upper and the lower limits are all grey numbers, $\otimes_{x}$ is called a black number.

Definition 3: When $\otimes_{\mathrm{x}} \in[\underline{\mathrm{x}}, \overline{\mathrm{x}}]$ and $\underline{\mathrm{x}}=\overline{\mathrm{x}}, \otimes_{\mathrm{x}}$ is called a white number.

Definition 4: For a general interval grey number $\otimes_{\mathrm{x}} \in[\underline{\mathrm{x}}, \overline{\mathrm{x}}]$, its whitenization value $\widetilde{\otimes}_{\mathrm{x}}$ is taken as $\widetilde{\otimes}_{\mathrm{x}}=\alpha \underline{\mathrm{x}}+$ $(1-\alpha) \bar{x}, \alpha \in[0,1]$ is called equal weight whitenization.

Definition 5: In an equal weight whitenization, the whitenization value, obtained when taking $\alpha=1 / 2$, is called an equal weight mean whitenization. When the distribution function of an interval grey number is hardly known, usually the equal weight mean whitenization is used. 


\section{MPI with Interval Grey Data}

In a set of DMUs, suppose the inputs $\otimes_{\mathrm{x}_{\mathrm{ij}}}=\left[\overline{\mathrm{x}_{\mathrm{ij}}}, \overline{\mathrm{x}_{\mathrm{ij}}}\right]$ and outputs $\otimes_{\mathrm{y}_{\mathrm{rj}}}=\left[\overline{\mathrm{y}_{\mathrm{j} j}}, \overline{\mathrm{y}_{\mathrm{rj}}}\right]$ are interval grey numbers at periods $t$ and $t+1$. Grey distance function model for $\mathrm{k}^{\text {th }} \mathrm{DMU}$ can be written as the following:

$$
\mathrm{D}_{\mathrm{o}}^{\mathrm{b}}(\otimes \mathrm{a})=\max \sum_{\mathrm{r}=1}^{\mathrm{s}} \mathrm{u}_{\mathrm{r}}\left[\underline{\mathrm{y}_{\mathrm{rk}}^{\mathrm{a}},}, \overline{\mathrm{y}_{\mathrm{rk}}^{\mathrm{a}}}\right] \quad \mathrm{a}=\mathrm{t}, \mathrm{t}+1 \quad \mathrm{~b}=\mathrm{t}, \mathrm{t}+1
$$

s.t.

$$
\begin{aligned}
& \sum_{r=1}^{s} u_{r}\left[\underline{y_{r j}^{b}}, \overline{y_{r j}^{b}}\right]-\sum_{i=1}^{m} v_{i}\left[\underline{x_{i j}^{b}}, \overline{x_{i j}^{b}}\right] \leq 0 \quad j=1, \ldots n \\
& \sum_{i=1}^{m} v_{i}\left[\underline{x_{i k}^{a}}, \overline{x_{i k}^{a}}\right]=1 \\
& v_{i}, u_{r} \geq 0 \quad \forall i, r
\end{aligned}
$$

\subsection{Proposed Model-I (PM-I)}

Step 1: The upper bound of distance function for $\mathrm{k}^{\text {th }}$ DMU happens when it produces maximum output by using minimum input, while other DMUs produce least output by using maximum input. So, upper bounds of distance functions can be calculated by (9) for single periods and with (10) for mixed periods.

$$
\overline{\mathrm{D}_{\mathrm{o}}^{\mathrm{a}}(\otimes \mathrm{a})}=\max \sum_{\mathrm{r}=1}^{\mathrm{s}} \mathrm{u}_{\mathrm{r}} \overline{\mathrm{y}_{\mathrm{rk}}^{\mathrm{a}}} \quad \mathrm{a}=\mathrm{t}, \mathrm{t}+1
$$

s.t.

$\sum_{r=1}^{s} u_{r} \underline{y_{r j}^{a}}-\sum_{i=1}^{m} v_{i} \overline{x_{i j}^{a}} \leq 0 \quad j=1, \ldots n \quad j \neq k$

$\sum_{\mathrm{i}=1}^{\mathrm{m}} \mathrm{v}_{\mathrm{i}} \underline{\mathrm{x}_{\mathrm{ik}}^{\mathrm{a}}}=1$

$\mathrm{v}_{\mathrm{i}}, \mathrm{u}_{\mathrm{r}} \geq 0 \quad \forall \mathrm{i}, \mathrm{r}$

$$
\| \begin{aligned}
& \overline{D_{0}^{b}(\otimes a)}=m a x \sum_{r=1}^{s} u_{r} \overline{y_{r k}^{a}} \quad a, b=t, t+1 \quad a \neq b \\
& \text { s.t. } \\
& \sum_{r=1}^{s} u_{r} \underline{y_{r j}^{b}}-\sum_{i=1}^{m} v_{i} \overline{x_{i j}^{b}} \leq 0 \quad j=1, \ldots n \\
& \sum_{i=1}^{m} v_{i} x_{i k}^{a}=1 \\
& v_{i}, u_{r} \geq 0 \quad \forall i, r
\end{aligned}
$$

Similarly, the lower bound of distance function for $\mathrm{k}^{\text {th }}$ DMU occurs once it produces the least output by using maximum input, whereas, other DMUs produce maximum output by using minimum input. Hence the lower bound models can be defined as (11) for single periods and as (12) for mixed periods.

$\underline{\mathrm{D}_{0}^{\mathrm{a}}(\otimes \mathrm{a})}=\max \sum_{\mathrm{r}=1}^{\mathrm{s}} \mathrm{u}_{\mathrm{r}} \underline{\mathrm{y} r \mathrm{a}} \quad \mathrm{a}=\mathrm{t}, \mathrm{t}+1$

s.t.

$\sum_{r=1}^{s} u_{r} \overline{y_{r j}^{a}}-\sum_{i=1}^{m} v_{i} x_{i j}^{a} \leq 0 \quad j=1, \ldots n \quad j \neq k$

$\sum_{\mathrm{i}=1}^{\mathrm{m}} \mathrm{v}_{\mathrm{i}} \overline{\mathrm{x}_{\mathrm{ik}}^{\mathrm{a}}}=1$

$\mathrm{v}_{\mathrm{i}}, \mathrm{u}_{\mathrm{r}} \geq 0 \quad \forall \mathrm{i}, \mathrm{r}$

s.t.

$\sum_{r=1}^{s} u_{r} \overline{y_{r j}^{b}}-\sum_{i=1}^{m} v_{i} x_{i j}^{b} \leq 0 \quad j=1, \ldots n$

$\sum_{\mathrm{i}=1}^{\mathrm{m}} \mathrm{v}_{\mathrm{i}} \overline{\mathrm{x}_{\mathrm{ik}}^{\mathrm{a}}}=1$

$\mathrm{v}_{\mathrm{i}}, \mathrm{u}_{\mathrm{r}} \geq 0$

Step 2: By using minimum and maximum values of distance functions, upper and lower bounds of MPI in order to $\mathrm{k}^{\text {th }} \mathrm{DMU}$ can be measured as below:

$$
\begin{aligned}
& \overline{M_{0}(\otimes)}=\left[\left(\frac{\overline{D_{0}^{t}(\otimes t+1)}}{\underline{D_{0}^{t}(\otimes t)}}\right)\left(\frac{\overline{D_{0}^{t+1}(\otimes t+1)}}{\underline{D_{0}^{t+1}(\otimes t)}}\right)\right]^{\frac{1}{2}} \\
& \underline{\mathrm{M}_{\mathrm{o}}(\otimes)}=\left[\left(\frac{\left.\frac{\mathrm{D}_{\overline{\mathrm{t}}(\otimes t+1)}^{\mathrm{t}(\otimes \mathrm{t})}}{\overline{\mathrm{D}}_{0}^{\mathrm{t}}}\right)}{\frac{\mathrm{D}_{0}^{\mathrm{t}+1}(\otimes \mathrm{t}+1)}{\overline{\mathrm{D}}_{\mathrm{t}}^{\mathrm{t}+1}(\otimes \mathrm{t})}}\right)\right]^{\frac{1}{2}}
\end{aligned}
$$

Step 3: The models (13) and (14) provide that possible MPI of $\mathrm{k}^{\text {th }}$ DMU which lies in a bounded interval 
$\left[\mathrm{M}_{\mathrm{o}}(\otimes), \overline{\mathrm{M}_{\mathrm{o}}(\otimes)}\right]$ which is an interval grey number. Since the distribution function of MPI is hardly known, the equal weight mean whitenization function in the definition 5 can be used to whitenize it with the following:

$$
\mathrm{M}_{\mathrm{o}}(\mathrm{PM}-\mathrm{I} \widetilde{\otimes})=1 / 2\left[\underline{\mathrm{M}_{0}(\otimes)}+\overline{\mathrm{M}_{\mathrm{o}}(\otimes)}\right]
$$

Due to the value of $\mathrm{M}_{0}(\mathrm{PM}-\mathrm{I} \widetilde{\otimes})$ is exact, it can be deduced that $\mathrm{M}_{\mathrm{o}}(\mathrm{PM}-\mathrm{I} \widetilde{\otimes})>1$ denotes productivity growth, while $\mathrm{M}_{\mathrm{o}}(\mathrm{PM}-\mathrm{I} \widetilde{\otimes})<1$ indicates productivity decline, and $\mathrm{M}_{\mathrm{o}}(\mathrm{PM}-\mathrm{I} \widetilde{\otimes})=1$ means no change in productivity from period to $\mathrm{t}+1$.

\subsection{Proposed Model II (PM-II)}

Step 1: If equal weight whitenization function at definition 4 is applied, interval grey inputs and outputs are obtained as below:

$$
\begin{aligned}
& \widetilde{\otimes}_{x_{i j}}=\alpha_{i j} \underline{x}_{i j}+\left(1-\alpha_{i j}\right) \bar{x}_{i j}, \quad \alpha_{i j} \in[0,1] \\
& \widetilde{\otimes}_{y_{r j}}=\beta_{r j} \underline{y}_{r j}+\left(1-\beta_{r j}\right) \bar{y}_{r j}, \quad \beta_{r j} \in[0,1]
\end{aligned}
$$

Step 2: Assume that $\alpha_{\mathrm{ij}}=\beta_{\mathrm{rj}}=\alpha$, then (4.1) can be converted into the following distance function model:

$$
\mathrm{D}_{\mathrm{o}}^{\mathrm{b}}(\otimes \mathrm{a})=\max \sum_{\mathrm{r}=1}^{\mathrm{s}} \mathrm{u}_{\mathrm{r}}\left[\overline{\mathrm{y}_{\mathrm{rk}}^{\mathrm{a}}}+\alpha\left(\underline{\mathrm{y}_{\mathrm{rk}}^{\mathrm{a}}}-\overline{\mathrm{y}_{\mathrm{rk}}^{\mathrm{a}}}\right)\right] \quad \mathrm{a}=\mathrm{t}, \mathrm{t}+1 \quad \mathrm{~b}=\mathrm{t}, \mathrm{t}+1
$$

s.t.

$$
\begin{array}{cc}
\sum_{r=1}^{s} u_{r}\left[\overline{y_{r j}^{b}}+\alpha\left(\underline{y_{r j}^{b}}-\overline{\left.y_{r j}^{b}\right)}\right]-\sum_{i=1}^{m} v_{i}\left[\overline{x_{i j}^{b}}+\alpha\left(\underline{x_{i j}^{b}}-\overline{\left.x_{i j}^{b}\right)}\right] \leq 0 \quad j=1, \ldots n\right.\right. \\
\sum_{i=1}^{m} v_{i}\left[\overline{x_{i k}^{a}}+\alpha\left(\underline{x_{i k}^{a}}-\overline{\left.x_{i k}^{a}\right)}\right]=1\right. \\
v_{i}, u_{r} \geq 0 \quad \forall i, r
\end{array}
$$

Step 3: (18) is a nonlinear model because of the variables $\mathrm{u}_{\mathrm{r}}, \mathrm{v}_{\mathrm{i}}$ and $\alpha$. In order to linearize that model, following substitutions can be applied:

$$
\left(\mathrm{d}_{\mathrm{r}}=\mathrm{u}_{\mathrm{r}} \alpha\right) \quad\left(\mathrm{h}_{\mathrm{i}}=\mathrm{v}_{\mathrm{i}} \alpha\right)
$$

Due to $0 \leq \alpha \leq 1$, it is possible to write:

$$
\mathrm{d}_{\mathrm{r}} \leq \mathrm{u}_{\mathrm{r}} \quad \mathrm{h}_{\mathrm{i}} \leq \mathrm{v}_{\mathrm{i}}
$$

Step 4: By these substitutions distance function model can be denoted as below:

$$
\mathrm{D}_{\mathrm{o}}^{\mathrm{b}}(\otimes \mathrm{a})=\max \sum_{\mathrm{r}=1}^{\mathrm{s}} \mathrm{u}_{\mathrm{r}} \overline{\mathrm{y}_{\mathrm{rk}}^{\mathrm{a}}}+\mathrm{d}_{\mathrm{r}}\left(\underline{\left(\mathrm{y}_{\mathrm{rk}}^{\mathrm{a}}\right.}-\overline{\mathrm{y}_{\mathrm{rk}}^{\mathrm{a}}}\right) \quad \mathrm{a}=\mathrm{t}, \mathrm{t}+1 \quad \mathrm{~b}=\mathrm{t}, \mathrm{t}+1
$$

s.t.

$$
\begin{array}{ll}
\sum_{r=1}^{s} u_{r} \overline{y_{r j}^{b}}+d_{r}\left(\underline{y_{r j}^{b}}-\overline{y_{r j}^{b}}\right)-\sum_{i=1}^{m} \frac{v_{i} x_{i j}^{b}}{x_{i j}}+h_{i}\left(\underline{x_{i j}^{b}}-\overline{x_{i j}^{b}}\right) \leq 0 & j=1, \ldots n \\
\sum_{i=1}^{m} v_{i} \overline{x_{i k}^{a}}+h_{i}\left(\underline{x_{i k}^{a}}-\overline{x_{i k}^{a}}\right)=1 & \\
d_{r}-u_{r} \leq 0 & \forall r \\
h_{i}-v_{i} \leq 0 & \forall i \\
d_{r}, h_{i}, u_{r}, v_{i} \geq 0 & \forall i, r
\end{array}
$$

Step 5: By using four distance functions which are obtained at step 4, MPI between periods $\mathrm{t}$ and $\mathrm{t}+1$ can be measured with the following equation:

$$
\mathrm{M}_{\mathrm{o}}(\mathrm{PM}-\mathrm{II} \otimes)=\left[\left(\frac{\mathrm{D}_{0}^{\mathrm{t}}(\otimes \mathrm{t}+1)}{\mathrm{D}_{\mathrm{o}}^{\mathrm{t}}(\otimes \mathrm{t})}\right)\left(\frac{\mathrm{D}_{\mathrm{t}+1}^{\mathrm{t}}(\otimes \mathrm{t}+1)}{\mathrm{D}_{0}^{\mathrm{t}+1}(\otimes \mathrm{t})}\right)\right]^{\frac{1}{2}}
$$

\subsection{Proposed Model III (PM-III, Extension of PM-II)}

If assumption in proposed model II is ignored, then substitutions at step 2 can be applied as,

$$
\left(\mathrm{d}_{\mathrm{rj}}=\mathrm{u}_{\mathrm{r}} \beta_{\mathrm{rij}}\right) \quad\left(\mathrm{h}_{\mathrm{ij}}=\mathrm{v}_{\mathrm{i}} \mathrm{\alpha}_{\mathrm{ij}}\right)
$$

By these substitutions distance function model can be rewritten as: 


$$
\mathrm{D}_{\mathrm{o}}^{\mathrm{b}}(\otimes \mathrm{a})=\max \sum_{\mathrm{r}=1}^{\mathrm{s}} \mathrm{u}_{\mathrm{r}} \overline{\mathrm{y}_{\mathrm{rk}}^{\mathrm{a}}}+\mathrm{d}_{\mathrm{rk}}\left(\underline{\mathrm{y}_{\mathrm{rk}}^{\mathrm{a}}}-\overline{\left.\mathrm{y}_{\mathrm{rk}}^{\mathrm{a}}\right)} \quad \mathrm{a}=\mathrm{t}, \mathrm{t}+1 \quad \mathrm{~b}=\mathrm{t}, \mathrm{t}+1\right.
$$

s.t.

$$
\begin{array}{ll}
\sum_{r=1}^{s} u_{r} \overline{y_{r j}^{b}}+d_{r j}\left(y_{r j}^{b}-\overline{\left.y_{r j}^{b}\right)}-\sum_{i=1}^{m} v_{i} \overline{x_{i j}^{b}}+h_{i j}\left(\underline{x_{i j}^{b}}-\overline{x_{i j}^{b}}\right) \leq 0 \quad j=1, \ldots n \quad(j \neq k \text { for single periods })\right. \\
\sum_{i=1}^{m} v_{i} \overline{x_{i k}^{a}}+h_{i k}\left(\underline{x_{i k}^{a}}-\overline{\left.x_{i k}^{a}\right)}=1\right. & \forall r \\
d_{r j}-u_{r} \leq 0 & \forall i \\
h_{i j}-v_{i} \leq 0 & \forall i, r, j
\end{array}
$$

Since it is possible that $\mathrm{d}_{\mathrm{rk}}=0, \mathrm{~h}_{\mathrm{ik}}=1, \mathrm{v}_{\mathrm{i}}=1$ and $\mathrm{d}_{\mathrm{rj}}=1, \mathrm{~h}_{\mathrm{ij}}=0, \mathrm{u}_{\mathrm{r}}=1$ are applicable in $(21)$, the variables necessarily take the values to maximize objective function and as a result model turns into upper bounds of distance functions. In this case, MPI can be calculated as follows:

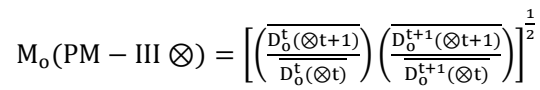

\begin{tabular}{|c|c|c|c|c|c|c|}
\hline \multirow{3}{*}{ DMU } & \multicolumn{6}{|c|}{ Periods } \\
\hline & \multicolumn{3}{|c|}{$\mathbf{t}$} & \multicolumn{3}{|c|}{$t+1$} \\
\hline & Output-I & Input-I & Input-II & Output-I & Input-I & Input-II \\
\hline $\mathbf{A}$ & {$[10,12]$} & {$[14,18]$} & {$[16,19]$} & {$[12,15]$} & {$[13,16]$} & {$[13,15]$} \\
\hline B & {$[11,14]$} & {$[18,20]$} & {$[9,11]$} & {$[15,17]$} & {$[15,18]$} & {$[8,9]$} \\
\hline C & {$[17,21]$} & {$[22,25]$} & {$[10,13]$} & {$[21,25]$} & {$[29,32]$} & {$[18,21]$} \\
\hline D & {$[20,24]$} & {$[15,17]$} & {$[26,29]$} & {$[23,27]$} & {$[26,28]$} & {$[30,34]$} \\
\hline E & {$[14,16]$} & {$[21,25]$} & {$[7,9]$} & {$[18,21]$} & {$[25,28]$} & {$[13,18]$} \\
\hline
\end{tabular}

\section{Numerical Example}

A numerical example is considered to illustrate the application of the models developed. The grey interval data of five DMUs which use two inputs to produce one output are given in table 1.

Table 1. Grey interval data of illustrative example

Measured MPIs of DMUs are given in table 2. Lower and upper bounds of MPIs for each DMU (possible MPI of a DMU lies within bounds) are shown in second column of table 2. It can be deduced from this column, because of $\overline{M_{0}(\otimes)}<1$, productivity of DMU D indicates a decline. Due to $\overline{M_{o}(\otimes)}>1$ and $\mathrm{M}_{\mathrm{o}}(\otimes)<1$, nothing can be said about productivity changes of the other DMUs.

Table 2. MPIs of DMUs

\begin{tabular}{ccccc}
\hline $\mathbf{D M U}$ & {$\left[\mathbf{M}_{\mathbf{o}}(\otimes), \overline{\mathbf{M}_{\mathbf{o}}(\otimes)}\right]$} & $\mathbf{M}_{\mathbf{o}}(\mathbf{P M}-\mathbf{I} \widetilde{\otimes})$ & $\mathbf{M}_{\mathbf{o}}(\mathbf{P M}-\mathbf{I I} \otimes)$ & $\mathbf{M}_{\mathbf{o}}(\mathbf{P M}-\mathbf{I I I} \otimes)$ \\
\hline $\mathbf{A}$ & {$[0.66,2.48]$} & 1.57 & 1.33 & 1.18 \\
$\mathbf{B}$ & {$[0.96,2.49]$} & 1.72 & 1.62 & 1.33 \\
$\mathbf{C}$ & {$[0.53,1.58]$} & 1.06 & 0.89 & 0.97 \\
$\mathbf{D}$ & {$[0.48,0.95]$} & 0.71 & 0.78 & 0.76 \\
$\mathbf{E}$ & {$[0.50,1.51]$} & 1.01 & 0.84 & 0.95 \\
\hline
\end{tabular}

MPIs of DMUs by using PMs are given in the third, fourth and last column of table 2 respectively. As shown in table 2, ranking of MPIs is the same $(B>A>C>E>D)$ and also productivities of DMU A and DMU B indicate growth while productivity of DMU D indicates decline according to all 3 methods. Productivities of DMU C and DMU D indicate decline by PM-II and PM-III whereas they indicate growth with reference to PM-I. 


\section{Conclusion}

In this paper, MPI models are developed to measure productivity changes of DMUs which have interval grey data. In the study, three different approaches are held by using grey whitenization functions. In the first approach, maximum and minimum values of inputs and outputs are used to measure upper and lower bounds of MPIs. As the distribution function of MPI is unknown; the equal weight mean whitenization function is used to whitenize the grey MPI. In the second approach, nonlinear distance function model is transformed into linear model by using variable substitutions under the assumption of all grey numbers have the same $\alpha$ and $\beta$ values. The only difference of the third approach from the second is that the values of $\alpha$ and $\beta$. In PM-III, different $\alpha$ and $\beta$ variable is defined to each DMU, input and output. We should indicate once again that as a limitation of the study, to be able to use the proposed methods, all interval grey numbers must have the equal (mean) weight whitenization function.

As it can be seen in the numerical example, the proposed models are easy to handle with grey data. As the paper shows that this kind of inter-method studies started to be investigated and there is a need growing in the literature. New theoretical attempts will not only test the validity of theoretical consequences but also provide a detailed horizon for new improvements.

\section{References}

Caves, D. W., Christensen, L. R., \& Diewert, W. E. (1982). The Economic Theory of Index Numbers and the Measurement of Input, Output, and Productivity. Econometrica, 50(6), 1414-1939. Retrieved from http://www.aae.wisc.edu/aae741/Ref/Caves\%20Econometrica\%201982.pdf

Chen, Y., \& Ali, A. I. (2004). DEA Malmquist Productivity Measure: New Insights with an Application to Computer Industry. European Journal of Operational Research, 159(1), 239-249. http://dx.doi.org/10.1016/S0377-2217(03)00406-5

Deng, J. L. (1982). Control problems of grey system. Systems and Control Letters, 1(5), 288-294. http://dx.doi.org/10.1016/S0167-6911(82)80025-X

Emrouznejada, A., Rostamy-Malkhalifeh, M., Hatami-Marbini, A., Tavana, M., \& Aghayi, N. (2011). An Overall Profit Malmquist Productivity Index with Fuzzy and Interval Data. Mathematical and Computer Modeling, 54, 2827-2838. http://dx.doi.org/10.1016/j.mcm.2011.07.003

Fare, R., Grosskopf, S., Lindgren, B., \& Ross, P. (1992). Productivity Changes in Swedish Pharmacies 1980-1989: A Non-Parametric Malmquist Approach. The Journal of Productivity Analysis, 3, 85-101. http://dx.doi.org/10.1007/BF00158770

Fare, R., Grosskopf, S., Norris, M., \& Zhang, Z. (1994). Productivity Growth, Technical Progress, and Efficiency Change in Industrialized Countries. The American Economic Review, 84(1), 66-83. Retrieved from http://www.iadb.org/res/files/dev2010/1994_productivity.pdf

Farrell, M. J. (1957). The Measurement of Productive Efficiency, Journal of the Royal Statistical Society, 120 , 253-290. Retrieved from http://www.aae.wisc.edu/aae741/Ref/Farrell\%201957.pdf

Hajiagha, S. H. R., Zavadskas, E. K., \& Hashemi, S. S. (2013). Application of Stepwise Data Envelopment Analysis and Grey Incidence Analysis to Evaluate the Effectiveness of Export Promotion Programs. Journal of Business Economics and Management, 14(3), 638-650. http://dx.doi.org/10.3846/16111699.2012.745819

Hatami-Marbini, A., Tavana, M., \& Emrouznejad, A. (2012). Productivity Growth and Efficiency Measurements in Fuzzy Environments with an Application to Health Care. International Journal of Fuzzy System Applications, 2(2), 35. http://dx.doi.org/10.4018/ijfsa.2012040101

Jahanshahloo, G. R., Lotfi, F. H., \& Valami, H. B. (2006). Malmquist Productivity Index with Interval and Fuzzy Data an Application of Data Envelopment Analysis. International Mathematical Forum, 1(33), 1607-1623. Retrieved from http://www.researchgate.net/profile/Hadi_Bagherzadeh_Valami/publication/254215273_Malmquist_Produc tivity_Index_with_Interval_and_Fuzzy_Data_An_Application_of_Data_Envelopment_Analysis/links/0a85

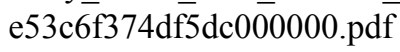

Jahanshahloo, G. R., Lotfi, F. H., Nikoomaram, H., \& Alimardini, M. (2007). Using a Certain Linear Ranking Function to Measure the Malmquist Productivity Index with Fuzzy Data and Application in Insurance Organization. Applied Mathematical Sciences, 1(14), 665-680. Retrieved from http://www.m-hikari.com/ams/ams-password-2007/ams-password13-16-2007/lotfiAMS13-16-2007-2.pdf 
Liu, S., \& Forrest, J. (2007). The Current Developing Status on Grey System Theory. The Journal of Grey System. 19 (2), 111-123. Retrieved from http://www.researchinformation.co.uk/grey/ CurrDevStatGreySysTheory.pdf

Liu, S., \& Lin, Y. (2006). Grey Information Theory and Practical Applications. London: Springer-Verlag.

Lotfi, H. F., Noora, A. A., Nikoomaram, H., Alimardani, M., \& Modi, M. (2009). Using LR-Fuzzy Numbers Data to Measure the Efficiency and the Malmquist Productivity Index in Data Envelopment Analysis and Its Application in Insurance Organizations. International Journal of Industrial Mathematics, 1(1), 55-68. Retrieved from http://www.sid.ir/en/VEWSSID/J_pdf/1016220090106.pdf

Malmquist, S. (1953). Index Numbers and Indifference Curves. Trabajos de Estatistica, 4, 209-242.

Payan, A., \& Sharifi, M. F. (2013). Scrutiny Malmquist Productivity Index on Fuzzy Data by Credibility Theory with an Application to Social Security Organizations. Journal of Uncertain Systems, 7(1), 36-49. Retrieved from http://www.worldacademicunion.com/journal/jus/jusVol07No1 paper04.pdf

\section{Copyrights}

Copyright for this article is retained by the author(s), with first publication rights granted to the journal.

This is an open-access article distributed under the terms and conditions of the Creative Commons Attribution license (http://creativecommons.org/licenses/by/3.0/). 